\title{
Towards a national agenda for youth?
}

I t's a decade since a comprehensive health policy framework for Australian children and young people aged 0-24 years was first released. ${ }^{1}$ The health of young Australians was an ambitious document that sought to place child and adolescent health within a broader context of social development. It proposed a greater integration and coordination of health with other services for the young and their families. Its intent was to promote prevention and positive development rather than treatment alone. The subsequent National Agenda for

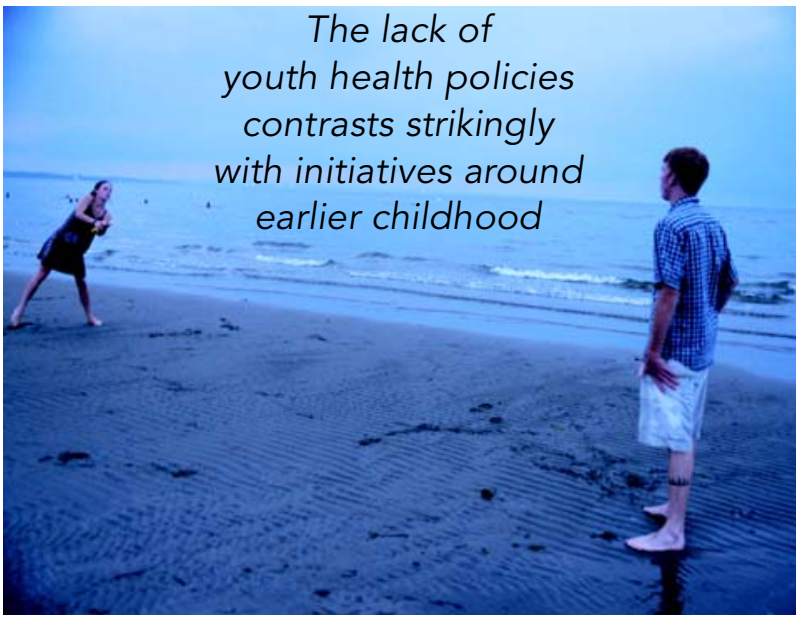

are to see similar overarching policies for youth. A background of economic growth, stable government, a focus on a knowledge-based society, and an understanding that we need a healthy and productive younger generation to support our increased longevity are all relevant. So too are concerns about the emergence of new psychosocial and health problems in young people. There are valuable lessons for advocates of broader youth health policies to learn from the work in early childhood. They include the use of data to drive integration of policy Early Childhood for children aged 0-5 years embodies many of these principles. ${ }^{2}$ Similarly, the closely aligned National Public Health Action Plan for Children aged 0-12 years draws on the earlier document. ${ }^{3}$

In striking contrast to these policy initiatives for children is the continued failure to articulate health policies for adolescents and young adults. It is not that needs of adolescents have diminished. ${ }^{4}$ Mental disorders, accidents and injuries, substance use and misuse, and reproductive and sexual health problems arise largely in this age group, with enormous health and social costs. ${ }^{4}$ Secular trends in mental disorders and substance use appear unfavourable; the health status of subgroups such as Indigenous young people and offenders is alarming; and adolescents remain the age group least likely to access health services and for whom health care providers feel least well equipped. ${ }^{5}$

So why have we failed to articulate policies for youth? Undoubtedly, the broader view of health and social development espoused in the 1995 framework challenged territorial boundaries within and between systems of government. Different legislative frameworks and professional development for people working across the sectors serving young people helped to reinforce the government silos. Paradoxically, the very recognition of the importance of the adolescent years for the emergence of specific health and social problems may have compounded the separation. The past decade has seen targeted initiatives around youth suicide, youth substance use, youth training and youth mental health as flagship policy initiatives within their particular areas of government. The Australian Government's recent plan to establish a \$69 million Foundation for Youth Mental Health is the most recent example. ${ }^{6}$ It is a welcome investment, with relevance for models of services provision in an age group in which major disorders of adulthood, such as depression, anxiety and schizophrenia, commonly emerge clinically. However, in the absence of an overarching policy framework for youth, it risks sitting mainly within the mental health service system. We might then see a well intentioned targeted policy initiative again fail to achieve effective prevention, an outcome that depends on youth mental health being a central outcome in sectors such as education, welfare, family and juvenile justice.

Timing and context were important for the emergence of the National Agenda for Early Childhood and remain important if we across sectors, accumulating evidence for practice, and building policy on a sensible conceptual base. We have a growing understanding of the factors in adolescence that influence transitions into and pathways out of health-compromising states. ${ }^{7}$ We know that puberty and the years that follow bring profound changes in emotional and cognitive function of young people, with implications for health and development well into later life. ${ }^{8}$ The quality of social contexts such as the family, secondary school and local community interact with these biological changes to affect health throughout the adolescent years., 90 Adverse influences during adolescence have the potential to undo gains made in earlier childhood. Moreover, preventive interventions in youth, such as intensive family-based interventions for young offenders, may be more cost-effective than interventions adopted early in life. ${ }^{11}$ The case for investment across the developmental years seems clear.

Since 1995, Australian models have come to the forefront internationally in adolescent health research and policy. ${ }^{10}$ Some "good buys" have emerged. Investment in primary and generic adolescent health care is, for example, likely to bring sustainable gains in the capacity of health service systems to be youth friendly, accessible and effective. ${ }^{12}$ So too, investments in middle and secondary schools bring sustained gains not only in education, but also in patterns of substance use and antisocial behaviour. ${ }^{9}$ However, an overarching policy framework requires more than good examples of integrated practice. Data systems addressing both health and social development are as important for guiding youth policies as for those for younger children. So, too, is the need to question assumptions underlying current child and youth policy. "Early in pathway" is not necessarily the same as "early in life". ${ }^{13}$ It is becoming increasingly clear that many problem pathways begin outside early childhood and the most effective interventions are targeted to the appropriate life phase, whether this be early or middle childhood or adolescence.

Finally, there is a question of who might drive an overarching policy agenda for youth. Coalitions such as the National Investment for the Early Years were important in promoting the early childhood agenda because they brought different sectors together to argue with one voice. Its success in broadening current policy debates to include a youth agenda will be one major test of the potency of newer cross-sectoral coalitions such as the Australian Research Alliance for Children and Youth. ${ }^{14}$ 


\section{POLICS CHANGES - EDITORIAL}

George C Patton

VicHealth Professor of Adolescent Health Research

Murdoch Childrens Research Institute, and Centre for Adolescent Health

University of Melbourne, VIC

george.patton@rch.org.au

Glenn Bowes

Stevenson Professor of Paediatrics, University of Melbourne, VIC

Susan M Sawyer

Professor of Adolescent Health, Department of Paediatrics University of Melbourne; and Director, Centre for Adolescent Health Royal Children's Hospital, Melbourne, VIC

Ross Homel

Professor of Criminology and Criminal Justice and Director, Key Centre for Ethics, Law, Justice and Governance Griffith University, Brisbane, QLD

Fiona J Stanley Professor of Paediatrics, University of Western Australia; and Director Telethon Institute for Child Health Research, Perth, WA

1 Commonwealth Department of Human Services and Health. The health of young Australians: a national health policy for children and young people. Canberra: Department of Human Services and Health, 1995. Available at: http://www7.health.gov.au/pubs/ythhlth/cyhpol.htm (accessed Sep 2005).

2 Commonwealth Task Force on Child Development Health and Welfare. Towards the development of a national agenda for early childhood. Canberra: Commonwealth of Australia, 2003. Available at: http:// www.facs.gov.au/internet/facsinternet.nsf/family/early_childhood.htm (accessed Sep 2005)

3 National Public Health Partnership. Healthy children - strengthening promotion and prevention across Australia. Developing a national public health action plan for children 2005-2008. Consultation paper. Melbourne: National Public Health Partnership, 2004. Available at: http://www.nphp.gov.au/workprog/chip/cyhactionplanbg.htm (accessed Sep 2005)
4 Australian Institute of Health and Welfare. Australia's young people: their health and wellbeing 2003. Canberra: AlHW, 2003. Available at: http:// www.aihw.gov.au/publications/index.cfm/title/9569 (accessed Sep 2005).

5 Veit F, Sanci L, Coffey $C$, et al. Barriers to adolescent health care: family physicians' perspectives. J Adolesc Health 1996; 18: 156.

6 Youth Mental Health Foundation to be established. Media release CP045/ 05. Canberra: Department of Health and Ageing, 22 July 2005. Available at: http://www.health.gov.au/internet/ministers/publishing.nsf/Content/healthmediarel-yr2005-cp-pyn045.htm (accessed Sep 2005).

7 Schofield PE, Borland R, Hill DJ, et al. Instability in smoking patterns among school leavers in Victoria, Australia. Tob Control 1998; 7: 149-155.

8 Patton GC, McMorris BJ, Toumbourou JW, et al. Puberty and the onset of substance use and abuse. Pediatrics 2004; 114: e300-e306.

9 Patton GC, Bond L, Butler H, Glover S. Changing schools, changing health? The design and implementation of the Gatehouse Project. J Adolesc Health 2003; 33: 231-239.

10 Loxley W, Toumbourou JW, Stockwell T, et al. The prevention of substance use, risk and harm in Australia: a review of the evidence. Canberra: Department of Health and Ageing, 2004. Available at: http://www.health.gov.au/ internet/wcms/publishing.nsf/Content/health-pubhlth-publicat-documentmetadata-mono_prevention.htm (accessed Sep 2005).

11 Aos S, Phipps P, Barnoski R, Lieb R. The comparative costs and benefits of programs to reduce crime. Version 4.0. Seattle: Washington State Institute for Public Policy, 2001. Available at: http://nicic.org/Library/020074 (accessed Sep 2005).

12 Sanci LA, Coffey C, Veit FCM, et al. Evaluation of an educational intervention for general practitioners in adolescent health care: randomised controlled study. BMJ 2000; 320: 224-230.

13 Pathways to prevention. Developmental and early intervention approaches to crime in Australia. Canberra: National Crime Strategy, Attorney General's Department, 1999. Available at: http://www.ag.gov.au/agd/WWW/ ncphome.nsf/Page/Publications (accessed Sep 2005).

14 Australian Research Alliance for Children and Youth [website]. Available at: http://www.aracy.org.au/ (accessed Sep 2005). 